\title{
Esquentou, esfriou, fermentou?
}

Did it get hot, cool, ferment?

Xisda Magna Rafaski dos Santos ${ }^{1}$, Karina Carvalho Mancini ${ }^{2}$, Andreia Barcelos Passos Lima Gontijo $^{2}$, Débora Barreto Teresa Gradella ${ }^{3}$

${ }^{1}$ Programa de Pós-Graduação em Rede em Ensino de Biologia (PROFBIO), Universidade Federal do Espírito Santo, São Mateus, Espírito Santo, Brasil.

${ }^{2}$ Universidade Federal do Espírito Santo, Departamento de Ciências Agrárias e Biológicas, São Mateus, Espírito Santo, Brasil.

${ }^{3}$ Universidade Federal do Espírito Santo, Departamento de Ciências da Saúde, São Mateus, Espírito Santo, Brasil.

Autor para correspondência: Xisda Magna Rafaski dos Santos

Escola Estadual de Ensino Médio Clóvis Borges Miguel

Avenida Corsanto, 164, Condomínio Vista dos Ipês, apto A 301, Residencial Vista dos Mestres, CEP 29.162-206, Serra, Espírito Santo, Brasil

Tel: +55 27 99965-2069

Email:xisda@hotmail.com

Submetido em 20/12/2020

Aceito em 21/12/2020 


\title{
RESUMO
}

$\mathrm{O}$ trabalho trata-se de uma proposta de atividade investigativa sobre o tema microrganismos e fermentação para as aulas de Biologia do ensino médio, tendo como objetivo entender a importância dos microrganismos, sua interação com outros seres vivos e o ambiente, caracterizando e diferenciando os principais grupos e discutir a participação benéfica dos fungos e bactérias, principalmente sobre a fermentação. Os resultados dos experimentos realizados ocorreram conforme esperado. A prática foi de simples execução, baixo custo, porém muito eficaz para se testar o que foi proposto, permitindo tornar do início ao fim o processo investigativo sem maiores dificuldades ou complicações.

Palavras-chave: Biologia. Microrganismos. Fermentação. Atividade Investigativa. Ensino.

\begin{abstract}
The work is a proposal for an investigative activity on the topic of microorganisms and fermentation for high school Biology classes with the objective of understanding the importance of microorganisms, their interaction with other living beings and the environment, characterizing and differentiating the main ones groups and discuss the beneficial participation of fungi and bacteria, especially on fermentation. The results of the experiments carried out occurred as expected. The practice was simple to perform, low cost, but very effective to test what was proposed allowing to make the investigative process from beginning to end without major difficulties or complications.
\end{abstract}

Keywords: Biology. Microorganisms. Fermentation. Investigative Activity. Teaching.

Health and Biosciences, v.1, n.3, Dez. 2020

Disponível em: https://periodicos.ufes.br/healthandbiosciences 


\section{INTRODUÇÃO}

Os microrganismos são importantes para a interação dos seres e manutenção do ambiente, comumente descritos nos livros didáticos e relacionados à importância ecológica e econômica. A fermentação é o processo biológico realizado por diversos tipos de microrganismos, como bactérias e fungos, e está presente no cotidiano dos estudantes de forma empírica quando observam ou preparam receitas de pães, iogurtes, coalhadas, queijos, entre outros. O álcool etílico (etanol) também tem seu destaque na indústria, pois é produzido a partir da fermentação da cana-de-açúcar realizada pela levedura Saccharomyces cerevisiae (AMABIS \& MARTHO, 2016).

Fermentação é um conteúdo que usualmente está inserido no estudo dos procariontes e fungos pertencentes, respectivamente, aos domínios Bactéria e EuKarya (LOPES \& ROSSO, 2016). Este conteúdo desperta curiosidade e interesse nos estudantes, favorecendo, portanto, a condução da aula pelo professor mediador e que, consequentemente, tende a ser mais prazerosa e produtiva. Entretanto, não é incomum que o professor esbarre em alguns desafios e dificuldades que permeiam o mundo da microbiologia, tais como 1) a generalização da classificação dos microrganismos, pois comumente seres como bactérias, fungos e protozoários são tratados como palavras sinônimas pelos alunos; 2) dificuldade em compreender que um organismo unicelular é um ser vivo 3) falta de materiais e equipamentos para viabilizar uma aula de microscopia e 4) desvalorização do papel benéfico desses organismos, pois há sempre maior ênfase no caráter patogênico de bactérias e fungos, evidenciando doenças que acometem outros seres vivos, sobretudo humanos. Dessa forma, caso estes desafios não sejam superados e bem trabalhados, podem contribuir para a abstração desse conteúdo, repercutindo num estudo superficial, ineficiente e confuso.

Nesse sentido, desenvolver este assunto numa perspectiva investigativa pode trazer vários benefícios ao processo ensino-aprendizagem, uma vez que esse tipo de proposta aguça a curiosidade e desperta maior interesse dos estudantes em buscar soluções para resolver problemas sobre os fenômenos presentes no cotidiano. Segundo Sasseron (2015, p. 58) o ensino por investigação "denota a intenção do professor em possibilitar o papel ativo de seu aluno na construção de entendimento sobre os conhecimentos científicos”. Assim, o entendimento sobre a formação de bolhas na liberação de $\mathrm{CO}_{2}$ pelos fungos do fermento biológico na produção de pão, ou descobrir dentro de um iogurte a presença de bactérias, como os lactobacilos vivos, é

Health and Biosciences, v.1, n.3, Dez. 2020

Disponível em: https://periodicos.ufes.br/healthandbiosciences 
altamente significativo para o estudante. As experiências cotidianas dos estudantes promovem uma contextualização que, para Carvalho (2013, p. 09) “[...]podem sentir a importância da aplicação do conhecimento construído do ponto de vista social.”.

Por isso, ofertar práticas que façam parte do cotidiano dos estudantes, como a de fermentação, podem ressignificar seu olhar sobre o mundo microbiológico, pois os reposicionam para um lugar de proximidade com sua vivência. Segundo Krasilchik (2008), aulas práticas de Biologia desempenham funções únicas na vida dos estudantes, permitindo observação de fenômenos, variabilidade individual biológica e ainda proporcionam trabalho em grupo. Como consequência, ocorre diminuição da abstração e sobretudo promove a desmistificação de que os microrganismos são meros causadores de doenças.

\section{OBJETIVOS}

Entender a importância dos microrganismos, bem como sua interação com outros seres vivos e com o ambiente.

$\checkmark$ Caracterizar e diferenciar os principais grupos de microrganismos.

$\checkmark$ Discutir sobre a participação benéfica dos microrganismos, como fungos e bactérias.

$\checkmark$ Estimular nos estudantes a curiosidade por meio de ações investigativas sobre fenômenos como fermentação.

$\checkmark$ Investigar a influência da temperatura no processo fermentativo

$\checkmark$ Correlacionar produtos do cotidiano como resultado da fermentação.

\section{METODOLOGIA}

\section{Materiais utilizados}

Cada kit de experimentação deverá conter:

- 2 Tubos de ensaio;

- Suporte para tubos de ensaio;

- 2 Balões de mesma cor $n^{\circ} 6$ ou 7 ;

- 2 colheres chá de Fermento Biológico;

- 2 colheres de chá de açúcar.

Health and Biosciences, v.1, n.3, Dez. 2020

Disponível em: https://periodicos.ufes.br/healthandbiosciences 
Ainda serão necessários:

- 3 Béqueres;

- $\quad$ Água em diferentes temperaturas (quente, fria e gelada);

- Quadro e pincel.

\section{Desenvolvimento}

Para o desenvolvimento das atividades são necessárias 03 aulas (de 55 minutos cada) com turmas de 30 a 35 estudantes da $3^{a}$ série do Ensino Médio. Sugere-se que a turma seja dividida em 6 grupos e que cada grupo receba um kit de experimentação.

$1^{a}$ aula: Problematização.

Nessa aula o professor deverá instigar a curiosidade do estudante, por meio da problematização. O intuito é provocar a percepção dos estudantes entre os alimentos apresentados e o fenômeno da fermentação. Para que isso ocorra o professor poderá usar recursos diversos, tais como: painel de imagens, exposição de alimentos ou utilização de vídeos. Como sugestão o professor poderá utilizar os seguintes vídeos: 1) Vinícolas de São Roque fazem a tradicional Pisa da Uva, Fala Brasil (2018), disponível em: https://youtu.be/FPIWrUC9yqc. 2) Alimente-se Bem: A História dos Alimentos/Trigo, Canal Futura (2016), disponível em: https://youtu.be/m83E1jGmnS4. 3) ES Rural: Família transforma fazenda em laticínio artesanal nas montanhas capixabas, TV Educativa ES (2017), disponível em: https://youtu.be/kOMwcjMS7CA.

Depois da apresentação dos recursos, o professor organiza a turma em 6 grupos e inicia as discussões com perguntas do tipo:

- Que fenômeno pode ser relacionado entre os alimentos apresentados e os microrganismos?

Desta forma, à medida que os grupos forem respondendo, o professor deve elencar no quadro suas respostas desenvolvendo um diálogo que possibilite discussões acerca de outras questões como:

- O que permite que esses processos aconteçam? É um processo químico? Físico? Biológico? Ambiental?

- O processo tem participação de organismos vivos? Explique.

- Como eles atuam? De que necessitam? O que geram?

Health and Biosciences, v.1, n.3, Dez. 2020

Disponível em: https://periodicos.ufes.br/healthandbiosciences 
- Que fenômenos são observados durante o processo?

- Que fatores podem interferir no processo? Como interferem?

Apesar da vasta possibilidade de discussões, no presente trabalho o professor deve conduzir a aula para investigar o fator temperatura no processo de fermentação, destacado anteriormente. A partir da discussão, cada grupo registra suas hipóteses e analisa, juntamente com o professor, formas experimentais de testá-las.

$2^{a}$ aula: Realizando os experimentos e testando as hipóteses.

Os estudantes devem ser encaminhados ao laboratório de Biologia e organizados em 6 grupos. A experimentação para verificação das hipóteses geradas pelos grupos, no presente trabalho, envolve a utilização do kit descrito anteriormente. Entretanto, é importante lembrar que outras formas experimentais podem surgir na discussão da aula 1 e serem executadas na aula 2 .

Em cada bancada haverá 2 tubos de ensaio e dentro deles serão adicionadas 1 colher de chá de fermento biológico, 2 colheres de chá de açúcar e água em temperaturas diversas, conforme descrição:

- Grupos 1 e 4: No $1^{\circ}$ tubo, fermento, açúcar e água quente. No $2^{\circ}$ tubo, fermento, açúcar e água gelada.

- Grupos 2 e 5: No $1^{\circ}$ tubo fermento, açúcar e água em temperatura ambiente. No $2^{\circ}$ tubo, fermento, açúcar e água gelada.

- Grupos 3 e 6: No $1^{\circ}$ tubo, fermento, açúcar e água em temperatura ambiente. No $2^{\circ}$ tubo, fermento, açúcar e água quente.

Com as devidas substâncias nos tubos, prenda um balão vazio na abertura de cada tubo. Sugere-se que cada grupo tenha uma cor de balão diferente. Mergulhe os tubos de ensaio num Becker contendo água na mesma temperatura dos respectivos tubos, por 5 min. Como sugestão, usar somente três béqueres, um contendo água gelada (para colocar os tubos com água gelada), um contendo água bem quente (para os tubos com água quente) e um com água em temperatura ambiente (para os tubos com água em temperatura ambiente), proporcionando iguais condições para o desenvolvimento do experimento para todos os grupos. Após os cinco minutos, os tubos

Health and Biosciences, v.1, n.3, Dez. 2020

Disponível em: https://periodicos.ufes.br/healthandbiosciences 
devem ser retirados dos béqueres e acomodados no suporte sobre as bancadas para observação.

Os estudantes devem fazer registros escritos e fotográficos (opcional) para melhor discussão dos resultados. É importante que os estudantes visitem os demais grupos vizinhos para analisar os experimentos em temperaturas distintas.

Neste experimento, os balões que estão nos tubos de ensaio com água em temperatura ambiente inflam, devido a liberação de $\mathrm{CO}_{2}$. Já nos tubos de ensaio com água quente, os balões não inflam e não se observa produção de gases, pois a temperatura alta desnatura as proteínas dos fungos presentes no fermento biológico. Nos tubos de ensaio com água gelada, os balões também não inflam, pois a temperatura mais baixa deixa os microrganismos com metabolismo baixo, não ocorrendo, portanto, a produção de bolhas pelo processo de fermentação.

$3^{a}$ aula: Análise, resultado e discussão

Após realização do experimento os estudantes discutirão os resultados diante das hipóteses levantadas na primeira aula. Assim, cada grupo é convidado a relatar sua confirmação ou não da hipótese formulada.

\section{PONTOS INVESTIGATIVOS DA ATIVIDADE}

No desenvolvimento de uma atividade de caráter investigativo são necessários a realização de etapas importantes, tais como: problematização ou reflexão sobre uma situação problema, formulação de hipóteses, análise e discussão coletiva dos resultados, retomada das hipóteses propostas para que se averigue a confirmação ou a refutação. Por último, todos os estudantes são convidados a um compartilhamento de ideias e experiências vividas, como forma avaliativa da atividade proposta e do processo ensino-aprendizagem adquirido.

\section{CONSIDERAÇÕES}

Seguem aqui algumas considerações, como um relato de experiência, da atividade desenvolvida. Os resultados dos experimentos saíram como esperados para todos os grupos e temperaturas. Ao iniciar a discussão dos resultados, foi pedido aos estudantes para fazerem a leitura de suas hipóteses. A grande maioria concordava que a temperatura influenciava no processo de fermentação e esperava que o calor aumentasse a velocidade da reação. Entretanto, 
o mais interessante é que o pensamento deles estava voltado apenas ao processo químico e não consideraram que o fermento continha organismos vivos e, portanto, que uma temperatura elevada mataria os fungos presentes no fermento biológico, inviabilizando o processo fermentativo.

Essa prática foi de simples execução, baixo custo, porém muito eficaz para se testar o que foi proposto, permitindo tornar do início ao fim o processo investigativo sem maiores dificuldades ou complicações.

\section{AGRADECIMENTOS}

O presente trabalho foi realizado com o apoio da Coordenação de Aperfeiçoamento de Pessoal de Nível Superior - Brasil (CAPES) - Código de financiamento 001.

\section{REFERÊNCIAS BIBLIOGRÁFICAS}

1. AMABIS JM, MARTHO JR. Biologia Moderna Amabis \& Martho 2, São Paulo: Moderna, 2016, 354p.

2. CARVALHO AMP, OLIVEIRA CMA, SCARPA DL, SASSERON LH, SEDANO L, BATISTONI e SILVA M, CAPECCHI MCVM, ABIB MLVS, BRICCIA V. Ensino de Ciências por Investigação: Condições de implementação em sala de aula. São Paulo: Cengage Learning, 2013, 164p.

3. KRASILCHIK M. Prática de Ensino de Biologia, São Paulo: Editora da Universidade de São Paulo, 2008, 200p.

4. LOPES SGBC, ROSSO S. Bio 2, 3.ed., São Paulo: Editora Saraiva, 2016, 386p.

5. SASSERON LH. Alfabetização científica, ensino por investigação e argumentação: relações entre ciências da natureza e escola. Ens Pesq Educ Ciênc 17: 49-67, 2015. 